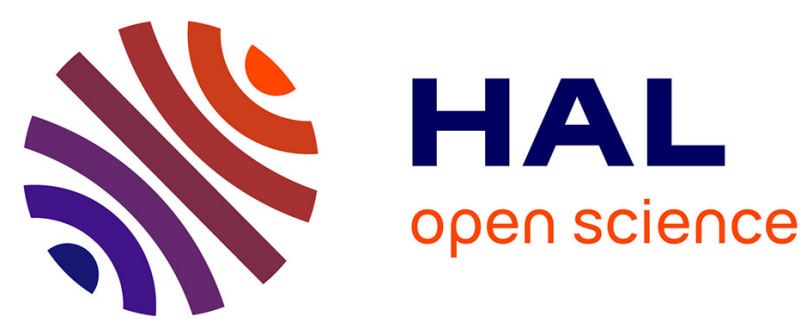

\title{
Hydrogen Storage in High Surface Area Carbon Nanotubes Produced by Catalytic Chemical Vapor Deposition
}

Revathi Bacsa, Christophe Laurent, Ryuta Morishima, Hiroshi Suzuki, Mikako Le Lay

\section{To cite this version:}

Revathi Bacsa, Christophe Laurent, Ryuta Morishima, Hiroshi Suzuki, Mikako Le Lay. Hydrogen Storage in High Surface Area Carbon Nanotubes Produced by Catalytic Chemical Vapor Deposition. Journal of Physical Chemistry B, 2004, vol. 108, pp. 12718-12723. 10.1021/jp0312621 . hal-00920911

\section{HAL Id: hal-00920911 \\ https://hal.science/hal-00920911}

Submitted on 19 Dec 2013

HAL is a multi-disciplinary open access archive for the deposit and dissemination of scientific research documents, whether they are published or not. The documents may come from teaching and research institutions in France or abroad, or from public or private research centers.
L'archive ouverte pluridisciplinaire HAL, est destinée au dépôt et à la diffusion de documents scientifiques de niveau recherche, publiés ou non, émanant des établissements d'enseignement et de recherche français ou étrangers, des laboratoires publics ou privés. 


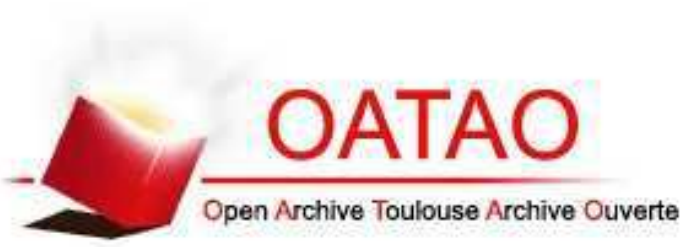

\section{Open Archive TOULOUSE Archive Ouverte (OATAO)}

OATAO is an open access repository that collects the work of Toulouse researchers and makes it freely available over the web where possible.

This is an author-deposited version published in : http://oatao.univ-toulouse.fr/ Eprints ID : 10548

To link to this article : DOI:10.1021/jp0312621

URL : http://dx.doi.org/10.1021/jp0312621

\section{To cite this version :}

Bacsa, Revathi and Laurent, Christophe and Morishima, Ryuta and Suzuki, Hiroshi and Le Lay, Mikako Hydrogen Storage in High Surface Area Carbon Nanotubes Produced by Catalytic Chemical Vapor Deposition. (2004) The Journal of Physical Chemistry B, vol. 108 (n 34). pp. 12718-12723. ISSN 1520-6106

Any correspondance concerning this service should be sent to the repository administrator: staff-oatao@listes-diff.inp-toulouse.fr 


\title{
Hydrogen Storage in High Surface Area Carbon Nanotubes Produced by Catalytic Chemical Vapor Deposition
}

\author{
Revathi Bacsa, ${ }^{\dagger}$ Christophe Laurent, ${ }^{*, \dagger}$ Ryuta Morishima, ${ }^{\ddagger}$ Hiroshi Suzuki, $;$ and \\ Mikako Le Lay ${ }^{\S}$ \\ CIRIMAT, UMR CNRS-UPS-INP 5085, Université Paul-Sabatier, 31062 Toulouse Cedex 4, France, \\ Toyota Motor Corporation, 1 Toyota-cho, Toyota city, Aichi pref., Japan, and Toyota Motor Engineering and \\ Manufacturing Europe, SA/NV, Zaventem, Belgium
}

\begin{abstract}
Carbon nanotubes, mostly single- and double-walled, are prepared by a catalytic chemical vapor deposition method using $\mathrm{H}_{2}-\mathrm{CH}_{4}$ atmospheres with different $\mathrm{CH}_{4}$ contents. The maximum hydrogen storage at room temperatures and $10 \mathrm{MPa}$ is $0.5 \mathrm{wt} \%$. Contrary to expectations, purification of the carbon nanotube specimens by oxidative acid treatments or by heating in inert gas decreases the hydrogen storage. Decreasing the residual catalyst content does not necessarily lead to an increase in ASH. Moreover, increasing the specific surface area does not necessarily increase the hydrogen storage capacity. There seems to be a correlation between the pore volume at low pore diameters $(<3 \mathrm{~nm})$ and the hydrogen storage capacity. Contribution from nanoscale disordered carbon to the hydrogen storage cannot be ruled out.
\end{abstract}

\section{Introduction}

Because of their large surface area, low density, and hollow structure, carbon nanotubes (CNTs) have been considered to be potential materials for hydrogen storage. Dillon et al. ${ }^{1}$ reported for the first time excellent hydrogen storage properties for a sample containing unpurified single-walled CNTs at 273 $\mathrm{K}$. Theoretical estimates based on Monte Carlo simulations in a grand canonical ensemble for closed and open CNTs have been reported, ${ }^{2-4}$ predicting that CNTs could be potentially attractive for hydrogen storage. Ye et al. ${ }^{5}$ measured hydrogen adsorption at low temperatures $(70 \mathrm{~K})$ on single-walled CNTs samples and concluded that the adsorption was proportional to the BET specific surface area. Thus, samples of individual CNTs were considered to be important for increased adsorption and as possible candidates for hydrogen storage. Other workers however reported that hydrogen storage capacity was higher in CNTs bundles wherein the adsorption sites were created under pressure. ${ }^{6}$ Hydrogen storage in CNTs was also reported to increase after etching surfaces of nanotubes with $\mathrm{NaOH} .^{7}$ Thus, the experimental data reported on both single-walled and multiwalled CNTs has been divergent and even contradictory. These results have been reviewed by Züttel et al. ${ }^{8}$ who emphasized that well-characterized samples combined with appropriate experimental techniques for measurement of hydrogen storage were necessary to obtain reproducible data.

In this context, we report the measurement of amount of stored hydrogen $(\mathrm{ASH}$, in wt \%) at room temperature and 10 MPa by a volumetric method on high specific surface area CNTs prepared by a catalytic chemical vapor deposition (CCVD) route. ${ }^{9}$ The advantage of this synthesis technique is the formation of predominantly individual, as opposed to bundled, CNTs which results in near-theoretical specific surface areas. ${ }^{10-12}$ The effect of standard purification treatments for CNTs on the hydrogen storage capacity was also tested. The present results show that the ASH values for a mixture of single- and doublewalled CNTs of diameter in the range $0.7-3 \mathrm{~nm}$ and specific surface areas of $550-850 \mathrm{~m}^{2} / \mathrm{g}$ lie in the range of $0.3-0.5 \mathrm{wt}$ $\%$ at room temperature and $10 \mathrm{MPa}$. It was observed that the ASH values decrease after purification of CNTs with nitric acid treatment or by heating in an inert gas. The samples were characterized by chemical analysis, Raman spectroscopy, electron microscopy and porosity measurements. The observed ASH values seem to depend on pore volumes in the less than $3 \mathrm{~nm}$ pore diameter range as calculated from adsorption isotherms for $\mathrm{N}_{2}$ gas at liquid $\mathrm{N}_{2}$ temperatures.

\section{Experimental Section}

Synthesis of Carbon Nanotubes. An oxide solid solution of the type $\mathrm{Mg}_{0.95} \mathrm{Co}_{0.05} \mathrm{O}$ was produced by combustion of the corresponding nitrates with urea, the details of which are given elsewhere. ${ }^{10,13}$ On heating the solid solution in $\mathrm{H}_{2}-\mathrm{CH}_{4}$ atmosphere, cobalt particles in the size range of 1-6 nm were produced in situ at a high temperature $\left(1000^{\circ} \mathrm{C}\right)$ which catalyzed the decomposition of $\mathrm{CH}_{4}$ and the formation of CNTs. The soobtained carbon nanotube $-\mathrm{Co}-\mathrm{MgO}$ composite powder was dropped into $1 \mathrm{M} \mathrm{HCl}$ at $25^{\circ} \mathrm{C}$ to separate the CNTs without damaging them..$^{9}$ The separated CNTs were washed with water and dried at $80^{\circ} \mathrm{C}$. It was possible to produce more than $1 \mathrm{~g}$ of separated CNTs in every run.

The important parameters in the above-mentioned synthesis are the concentration of active cobalt particles at a particular temperature and the availability of methane gas at this temperature. ${ }^{14}$ For the present study, the cobalt content in the oxide solid solution was fixed $\left(\mathrm{Mg}_{0.95} \mathrm{Co}_{0.05} \mathrm{O}\right)$ and the $\mathrm{CH}_{4}$ partial pressure in the $\mathrm{H}_{2}-\mathrm{CH}_{4}$ atmosphere was varied in the range 20-50 mol \%. The samples thus prepared are named D1, D2, D3, and D4 for $\mathrm{CH}_{4}$ contents of 20, 30, 40, and $50 \mathrm{~mol} \%$, respectively. 
Characterization. The CNTs specimens were characterized by scanning electron microscopy and high-resolution transmission electron microscopy (TEM). The carbon content was analyzed by flash combustion, and the cobalt content was calculated therefrom. These values were confirmed by EDX spectra recorded on selected areas at a magnification of 100000 during TEM observations. Raman spectroscopy was used to assess the nature of carbon. Raman spectra were recorded using a Micro-Raman setup (DILORXY), using backscattering geometry at $488 \mathrm{~nm}(3-8 \mathrm{~mW})$. The sample was placed on a bilayer substrate to enhance the Raman signal or alternatively on a microscope slide. Low-frequency breathing modes were used to estimate the CNTs diameter distribution in the less than $1.8 \mathrm{~nm}$ range. Comparison of the relative intensities of the $\mathrm{G}$ band (ca. $1580 \mathrm{~cm}^{-1}$ ) and the D band (ca. $1360 \mathrm{~cm}^{-1}$ ) were used to qualitatively estimate the amount of disordered carbon. BET specific surface areas (SSA) and pore size distributions were calculated by plotting the adsorption isotherm of $\mathrm{N}_{2}$ at liquid $\mathrm{N}_{2}$ temperature. The measurements were made on a Micromeritics ASAP 2010 porosimeter. The sample was degassed at $250{ }^{\circ} \mathrm{C}$ for $4-8 \mathrm{~h}$ before measurement. The pore size distributions were calculated using the adsorption branch of the isotherm using the $\mathrm{BJH}$ distribution equation.

Purification of Carbon Nanotubes. Various methods have been reported in the literature for the purification of CNTs. ${ }^{15-18}$ The principal impurity in the present CCVD CNTs specimens consists of poisoned cobalt particles encapsulated in carbon shells which resist the $\mathrm{HCl}$ attack. To decrease the proportion of this metal impurity, two methods were used: a nitric acid treatment followed by a heat-treatment in air and a heattreatment in argon at elevated temperatures followed by another $\mathrm{HCl}$ attack.

Following experimental methods reported in the literature, selected CNTs specimens (D1 and D3) were boiled in concentrated $\mathrm{HNO}_{3}$ at $120{ }^{\circ} \mathrm{C}$ for $4 \mathrm{~h}$. After centrifugation, washing and drying, the specimens were heated (heating rate $4{ }^{\circ} \mathrm{C} / \mathrm{min}$ ) in air up to $580{ }^{\circ} \mathrm{C}$ and maintained at this temperature for 10 min. The total weight loss after the two treatments was $80 \%$ in some cases, showing that some fraction of the CNTs were also destroyed. The chemical purity of the sample was assessed by EDX spectra on selected area. The amount of disordered carbon was assessed using Raman spectroscopy. The so-produced samples are named D1* and D3*. Carbon element analysis of nitric acid purified samples did not yield conclusive results due to the presence of oxygen in the form of functional groups on the surface of the CNTs.

In the second purification method, selected specimens (D1, D2, and D3) were heated in flowing argon atmosphere to 1000 ${ }^{\circ} \mathrm{C}$, maintained for $30 \mathrm{~min}$, and then cooled in argon. After the heat-treatment, the samples were dropped in $6 \mathrm{M} \mathrm{HCl}$. Effervescence due to evolution of $\mathrm{H}_{2}$ was seen and the solution turned rose showing the dissolution of cobalt metal. These samples were termed D1', D2', and D3'. The carbon content was determined by flash combustion.

Determination of the Amount of Stored Hydrogen (ASH). The amount of stored hydrogen (ASH, in wt \%) was measured by a volumetric method with hydrogen pressured up to $10 \mathrm{MPa}$ at room temperature. The measuring device is shown in Figure 1. The ASH is obtained from the desorbed gas amount, which is measured by the accurate flow-meter with $0.1 \mathrm{wt} \%$ of measurement error. Pressure is corrected every time by measuring the gas amount in the blank holder before measuring the gas amount in the sample holder. The line unit temperature is controlled uniformly.

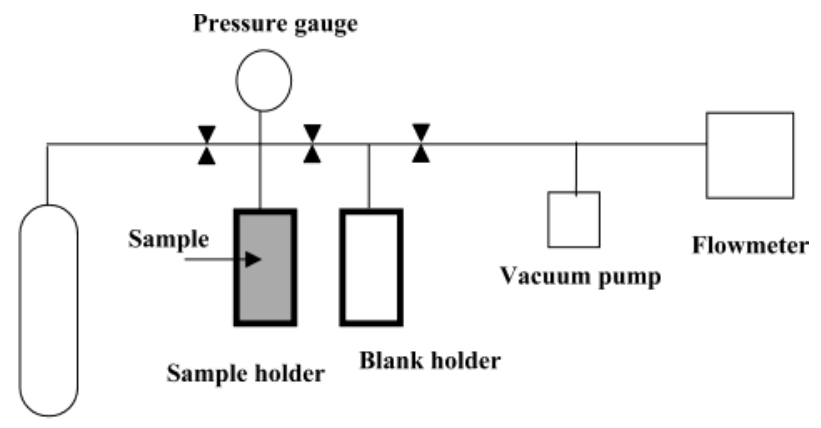

$\mathrm{H}_{2}$ gas tank

Figure 1. Schematic description of the device for the measurement of the amount of stored hydrogen (ASH).

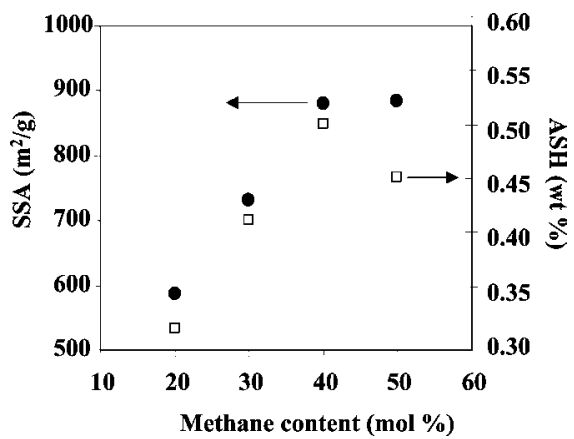

Figure 2. Specific surface area (SSA) and amount of stored hydrogen (ASH) for CNTs samples prepared using different $\mathrm{CH}_{4}$ content in the $\mathrm{H}_{2}-\mathrm{CH}_{4}$ atmosphere.

TABLE 1: Carbon Content, Cobalt Content (Other Impurities Include Traces of Chlorine and Oxygen), BET Specific Surface Area (SSA), Cumulative Volume of Pore < $3 \mathrm{~nm}$, and Amount of Stored Hydrogen (ASH) for As-Prepared Carbon Nanotube Samples (D1-D4) and Purified Samples $\left(\mathrm{D1} *, \mathrm{D3}^{*} \text {, and } \mathrm{D1}^{\prime}-\mathrm{D3}^{\prime}\right)^{a}$

\begin{tabular}{cccccc}
\hline sample & $\begin{array}{c}\text { carbon } \\
(\text { wt \%) }\end{array}$ & $\begin{array}{c}\text { cobalt } \\
(\text { wt \% })\end{array}$ & $\begin{array}{c}\text { BET SSA } \\
\left(\mathrm{m}^{2} / \mathrm{g}\right)\end{array}$ & $\begin{array}{c}\text { pore vol < 3 nm } \\
\left(\mathrm{cm}^{3} / \mathrm{g} \AA\right)\end{array}$ & $\begin{array}{c}\text { ASH } \\
(\text { wt \% })\end{array}$ \\
\hline D1 & 74 & 21.0 & 587 & 0.098 & 0.34 \\
D2 & 83 & 15.8 & 763 & 0.123 & 0.42 \\
D3 & 90 & 9.0 & 881 & 0.242 & 0.51 \\
D4 & 91 & 9.0 & 885 & 0.127 & 0.46 \\
D1* & 86 & 0.2 & 612 & 0.118 & 0.25 \\
D3* & & & 313 & 0.054 & 0.20 \\
D1 $^{\prime}$ & 85 & 9.7 & 746 & 0.125 & 0.25 \\
D2 $^{\prime}$ & 86 & 2.9 & 736 & 0.120 & 0.41 \\
D3 $^{\prime}$ & 89 & 2.4 & 659 & 0.110 & 0.27
\end{tabular}

${ }^{a}$ See text for details on the purification procedures.

\section{Results and Discussion}

As-prepared (unpurified) carbon nanotubes. Carbon element analysis of specimens D1-D4 (Table 1) showed that the carbon content is increased as the $\mathrm{CH}_{4}$ content is increased from 20 to 50 vol \% $(74,83,90$, and $91 \mathrm{wt} \%$ for D1, D2, D3, and D4, respectively). The cobalt content accordingly decreases (Table 1). The BET SSA and ASH of samples D1-D4 are reported in Table 1 and Figure 2. The BET SSA increases from D1 (587 $\left.\mathrm{m}^{2} / \mathrm{g}\right)$ sharply up to D3 $\left(881 \mathrm{~m}^{2} / \mathrm{g}\right)$ thereafter, showing a plateau. The ASH at room temperature and $10 \mathrm{MPa}$ increases up to D3 and sharply decreases thereafter. The ASH for all samples are less than 1 wt $\%$. This value, while being considerably lower than that reported by Dillon et al., ${ }^{1}$ is in general agreement with the values reported in the review by Züttel et al. ${ }^{8}$ for CNTs samples from various sources.

Samples D1-D3 were studied more closely in order to investigate the influence of the $\mathrm{CH}_{4}$ content during the synthesis. 


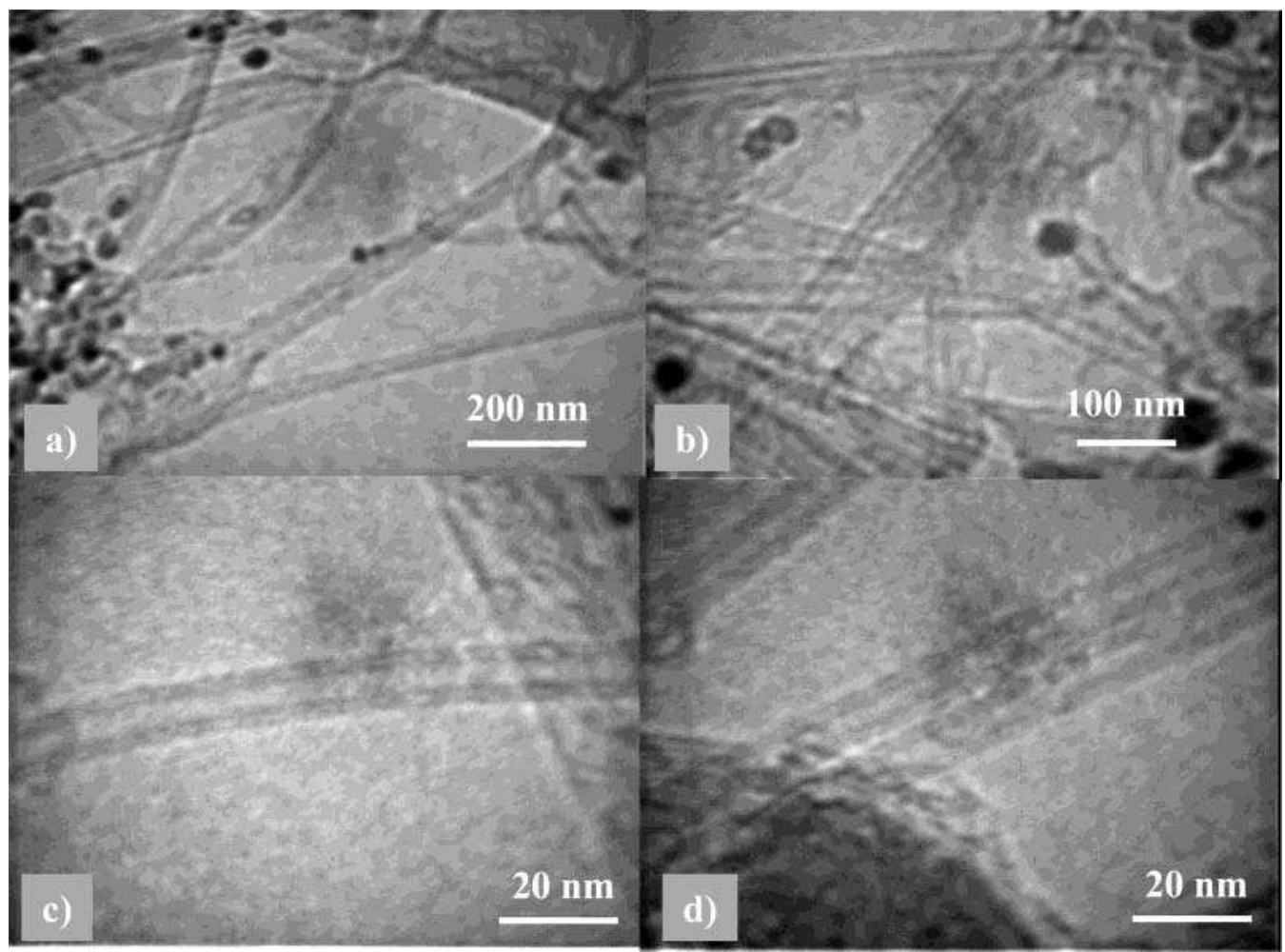

Figure 3. Typical TEM images, showing (a and b) CNTs and cobalt particles (dark contrast), a double-walled nanotube (c), and two side-by-side double-walled nanotubes (d).

Increasing it will tend to increase the carbon content in the samples, as shown above, but two distinct reasons, or a combination of both, can account for this result. Indeed, a key point of the synthesis is to match the carbon source (here $\mathrm{CH}_{4}$ ) to the metal content so as to produce as many CNTs as possible through the catalytic decomposition of $\mathrm{CH}_{4}$ at the surface of the Co particles, while avoiding the thermal decomposition of $\mathrm{CH}_{4}$ which will produce disordered, nontubular carbon. So the carbon content increase could reflect a higher CNTs content in the sample and/or the formation of nontubular carbon.

Typical TEM images are shown in Figure 3, revealing CNTs and cobalt particles that appear with a dark contrast (Figure 3a, Figure 3b), a double-walled nanotube (Figure 3c), and two sideby-side double-walled nanotubes (Figure 3d). The distributions of the number of walls of CNTs in D1 and D3 as well as the distribution of the inner and outer diameters, derived from the measurements of 128 individual CNTs for each sample on highresolution TEM images, are shown in Figure 4. About $90 \%$ of the CNTs are either single- or double-walled. The inner and outer diameter distributions are in the ranges $0.5-3.0$ and $0.75-$ $4.0 \mathrm{~nm}$, respectively. TEM images also showed a lower content of poisoned (i.e., inactive) cobalt particles with increasing $\mathrm{CH}_{4}$ content. Thus, it appears that the increased partial pressure of methane helps in preventing the poisoning of the cobalt particles, thereby accounting at least partly for the formation of more CNTs. Poisoned cobalt particles are the main impurity in the case of D1, D2, and D3 show in addition some disordered carbon which appear as flakes, the detailed structure of which is difficult to resolve. The flakes apparently consisted in one or two graphene sheets, and the CNTs were seen embedded on the flakes, forming an intimate composite structure (Figure 5).

Raman spectra of D1-D3 (Figure 6) show an increasing D band, revealing that the proportion of disordered carbon increases as the methane content is increased, in good agreement with the TEM study. The low-frequency radial breathing modes for specimen D1 (inset) shows several peaks corresponding to
CNTs with different diameters in the range $0.75-1.8 \mathrm{~nm}$, showing that no one diameter is preferred. In fact, the very lowdiameter CNTs are found to be mostly the internal wall of double-walled tubes. ${ }^{19}$

Purified Carbon Nanotubes. After nitric acid treatment followed by oxidation in air, the cobalt contents could be reduced to less than $1 \%$ in D1* and D3*. However, EDX analysis revealed that the purified samples showed the presence of oxygen, as compared to none at all in the as-prepared samples. It is possible therefore that extensive CNTs opening and functionalization takes place during the purification. IR spectra (not shown) have revealed the presence of carbonyl groups.

Figure 7 a shows a typical image of $\mathrm{D} 1 *$, revealing a very clean specimen. A closer look at the TEM images of purified samples showed that many of the open CNTs were filled with disordered carbon (Figure $7 \mathrm{~b}$ ). Thus, the nitric acid treatment cuts the CNTs and probably creates fragments of disordered carbon and these fill the CNTs during the thermal treatment in air. Raman spectra showed that little or no disordered carbon is present after purification. The Raman spectrum for D1* (Figure 8) shows a low-intensity D band. The BET SSA of D1* is of the order of that of D1, while the BET SSA of D3* (313 $\left.\mathrm{m}^{2} / \mathrm{g}\right)$ is much lower than that of D3 $\left(881 \mathrm{~m}^{2} / \mathrm{g}\right)$. This could reflect the initial proportion of nontubular carbon in D3.

The purification treatments, contrary to expectation, decrease the ASH values (Table 1). The decrease is particularly evident in the case of D3 and D3*, but despite that all characterization show the high chemical purity and structural homogeneity of D1*, the ASH value also show a decrease. Thus, the presence of metal impurity has little or no influence on the ASH values. The presence of open CNTs also does not influence the ASH values. It is probable that the opening of the present CNTs is accompanied by their functionalization which blocks potential adsorption. Indeed, Hirscher et al. ${ }^{18}$ have studied the influence of cutting CNTs on hydrogen adsorption and concluded that cutting has to be clean and hydrogen has to be introduced in 


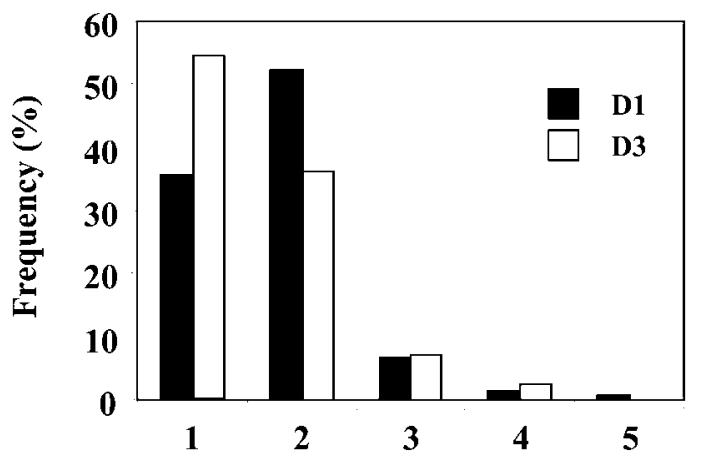

a)
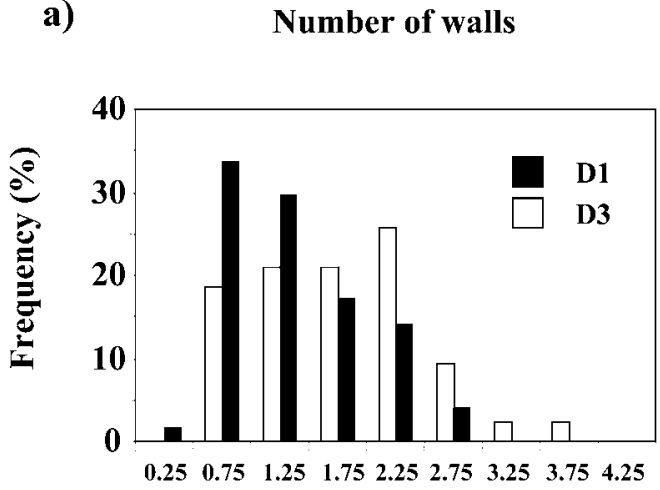

b)

Inner diameter (nm)

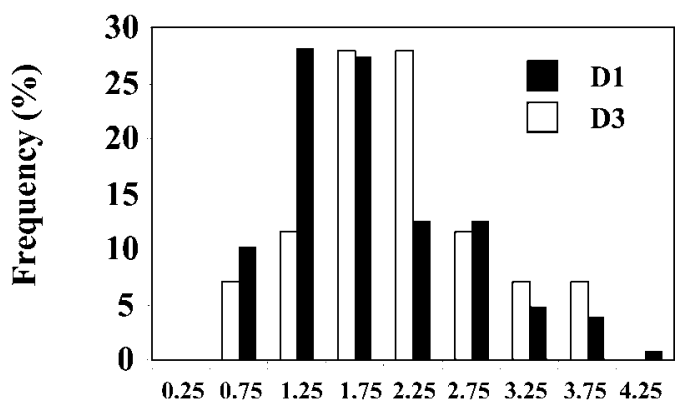

c)

Outer diameter (nm)

Figure 4. Distribution of the number of walls (a) and of the inner (b) and outer diameters (c) for CNTs in specimens D1 and D3. 128 CNTs were measured on high-resolution TEM images for each sample. The diameter of a nanotube in the " $0.75 \mathrm{~nm}$ " class is as follows: $0.5 \leq$ diameter $<1.0 \mathrm{~nm}$.

situ in order to increase adsorption. The sharp reduction of ASH values from D3 to D3* indicates that the presence of disordered carbon could also play an important role in the adsorption of hydrogen.

The first step of the second purification procedure is a heattreatment in argon at $1000{ }^{\circ} \mathrm{C}$. No major weight loss was observed after the heat-treatment. However, TEM images and EDX spectra showed that some poisoned cobalt particles migrate from their carbon shells and coalesce to form micrometer-sized spheres, leaving behind empty carbon shells. However, some cobalt particles, particularly those larger than $10 \mathrm{~nm}$ did not migrate out of their shells. How this phenomenon was produced in the absence of oxygen (no weight loss was observed), remains unclear. Perhaps cobalt particles in the size range of 1-6 nm are highly mobile at $1000{ }^{\circ} \mathrm{C}$ and hence can diffuse out of the carbon shells which surrounds them even if there is no oxidation of the carbon shell. Some CNTs are open and disordered carbon is seen inside and on the outer walls. It is interesting to note that in contrast to CNTs prepared by arc discharge and laser

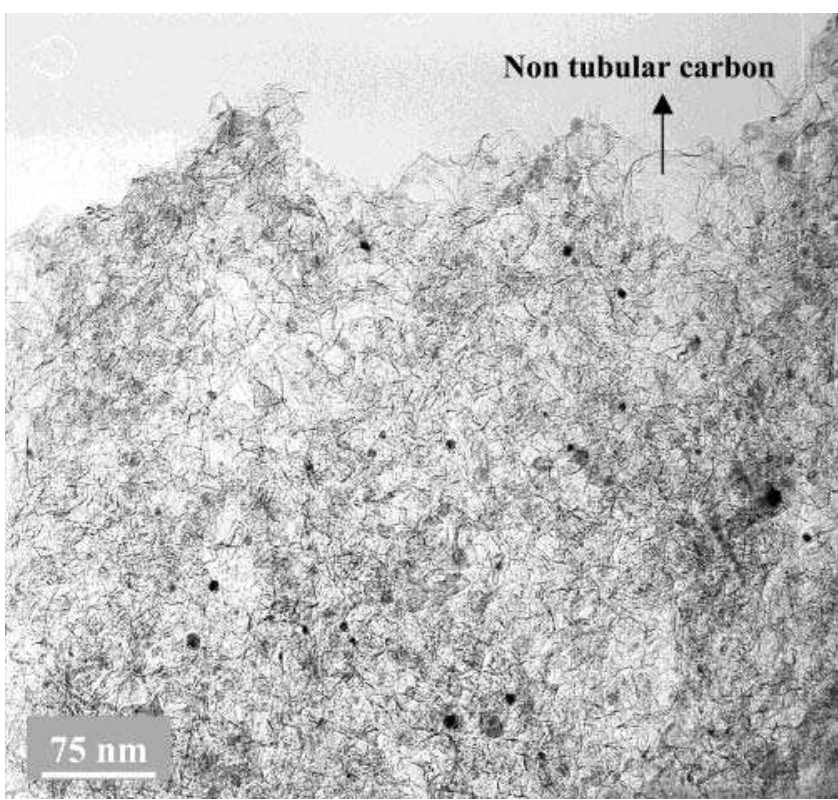

Figure 5. Typical TEM image D3 with disordered carbon in the form of flakes, forming an intimate composite structure with the CNTs.

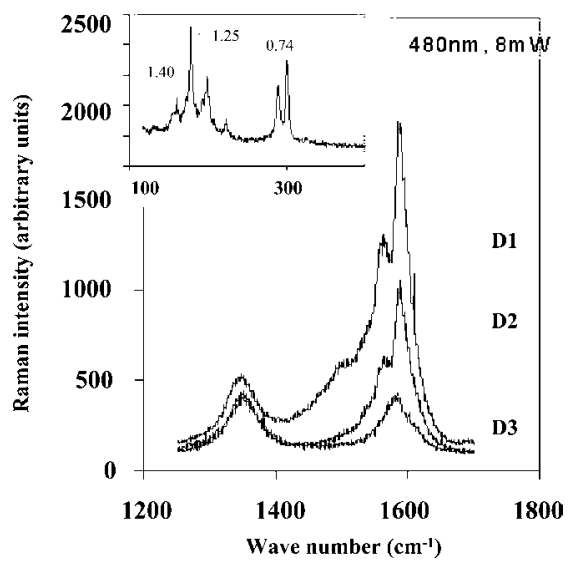

Figure 6. Raman spectra (488 nm) of samples D1, D2, and D3. The spectra show a band (G band close to $1580 \mathrm{~cm}^{-1}$ ) due to optical phonons in curved graphite sheets and a band (D band close to $1360 \mathrm{~cm}^{-1}$ ) due to defect induced scattering. The inset shows the low-frequency modes sensitive to CNTs diameter for D1. Some diameters (nm) are indicated.

ablation of graphite, the present CCVD CNTs are not stable at temperatures higher than $1000{ }^{\circ} \mathrm{C}$ even in inert atmosphere. This instability may be due to the presence of more defects in the as-prepared CNTs due to the lower synthesis temperature or to the presence of extremely small catalyst particles $(0.8-3 \mathrm{~nm})$ which may be highly mobile at temperatures much lower than the melting point of cobalt.

The second step of this purification procedure is a soaking in $6 \mathrm{M} \mathrm{HCl}$, which dissolves the now unprotected cobalt particles, giving rise to a strong effervescence. Element analysis show that the cobalt content is much lower in the $\mathrm{D}^{\prime}-\mathrm{D} 3^{\prime}$ samples than in the parent D1-D3 specimens (Table 1). No functionalization of the CNTs was observed and a high BET SSA (Table 1) were maintained. The ASH values are also decreased for these purified specimens, except for D2' which shows an ASH very similar to than of D2 (Table 1).

Thus, both the acid purification treatment and the argon treatment reduce the ASH values even though the acid treatment tends to decrease the specific surface area and the argon treatment increases it slightly. Thus, it appears that although 


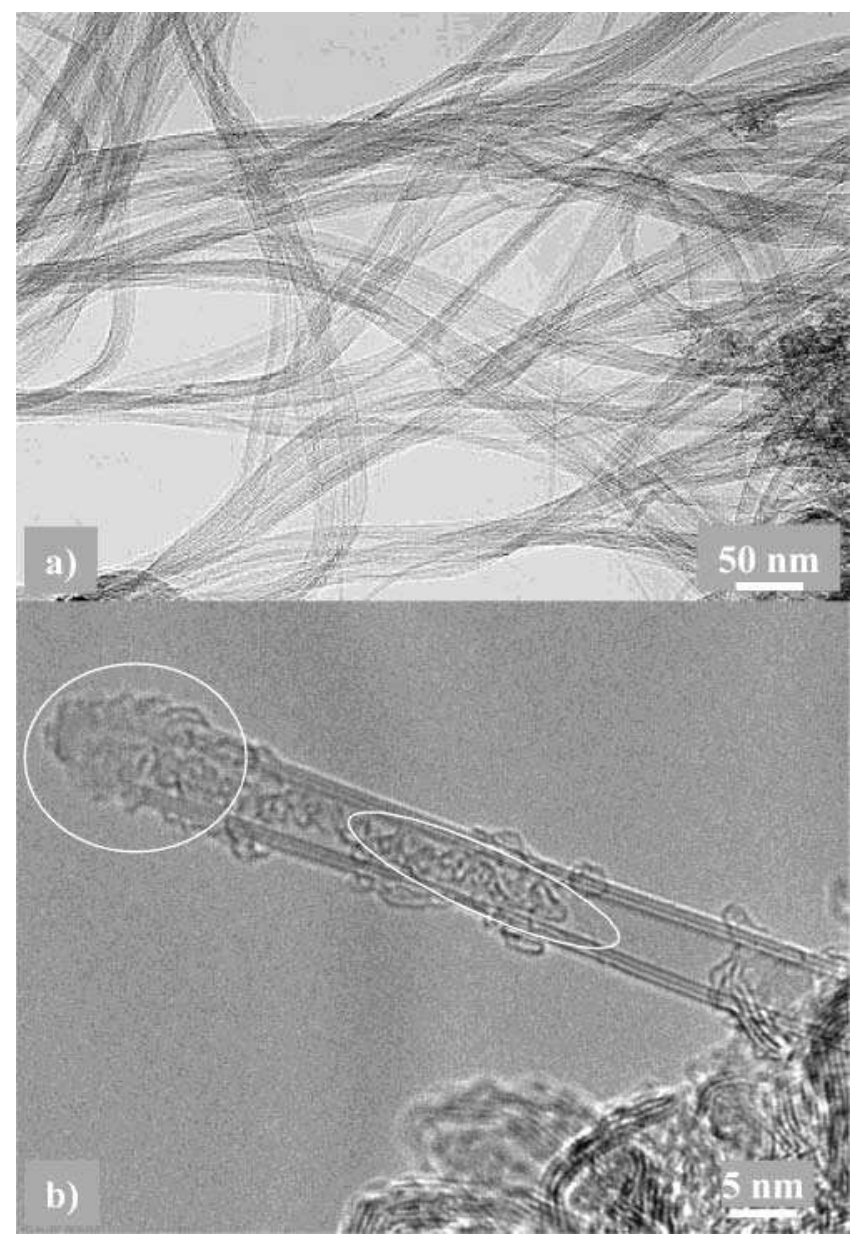

Figure 7. (a) Typical TEM image of the purified sample D ${ }^{*}$, revealing a very clean specimen. (b) TEM image showing a nanotube that had been opened and filled with disordered carbon in the purification process.

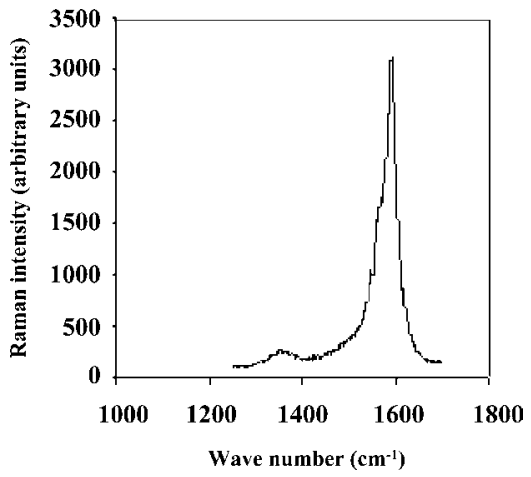

Figure 8. Raman spectrum $(488 \mathrm{~nm})$ of $\mathrm{D} 1 *$. Compare with the spectrum of D1 in Figure 5.

the trend is that the ASH increases with increasing SSA (Figure 9a), it does not depend only on SSA, and other factors are involved.

To explain these results, the adsorption properties of the different samples were studied by measuring the $\mathrm{N}_{2}$ adsorption isotherm at liquid $\mathrm{N}_{2}$ temperatures. The pore size distributions were calculated using the BJH equation from the adsorption branch of the isotherm. The cumulative pore volume in the range 1.8-3 nm was estimated therefrom (Table 1). The pores of higher dimensions were disregarded as being due to the secondary structure of nanotubes. The ASH values are plotted as a function of this pore volume (Figure 9b). There seems to
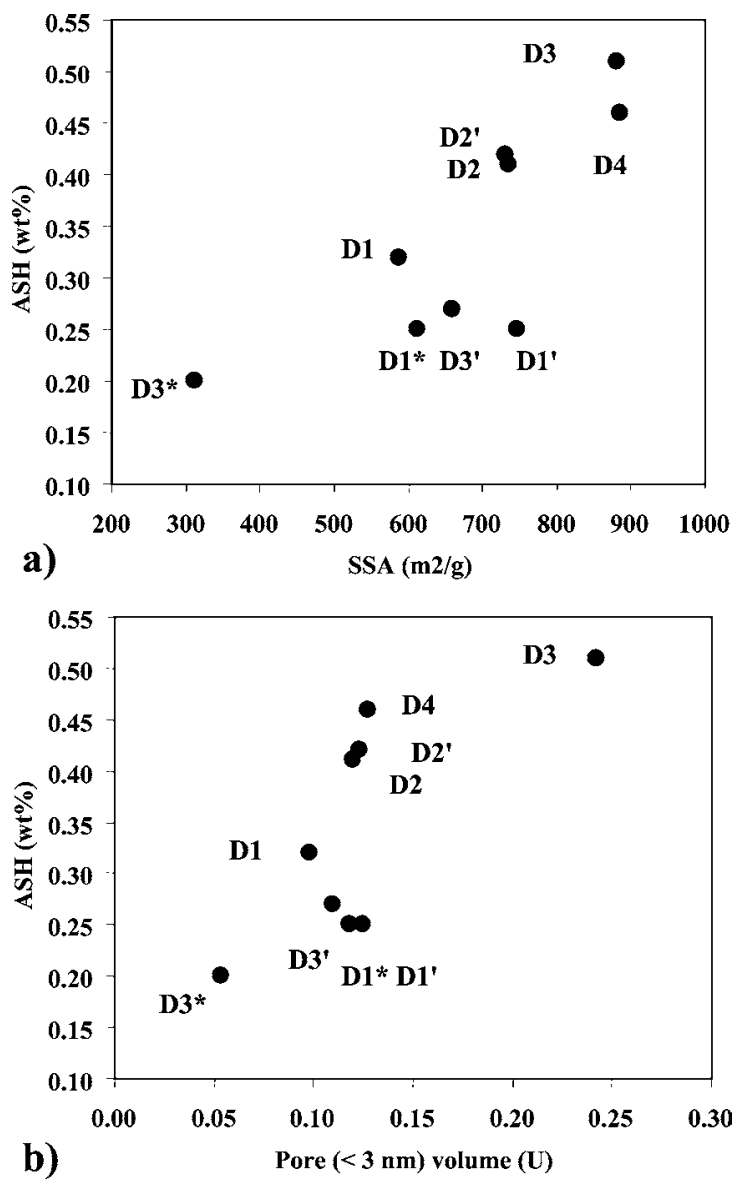

Figure 9. Amount of stored hydrogen (ASH), for all samples, vs (a) the specific surface area (SSA) and (b) vs the volume of pores $<3 \mathrm{~nm}$ calculated using the $\mathrm{BJH}$ equation using the adsorption branch of the $\mathrm{N}_{2}$ adsorption isotherm at $80 \mathrm{~K}$.

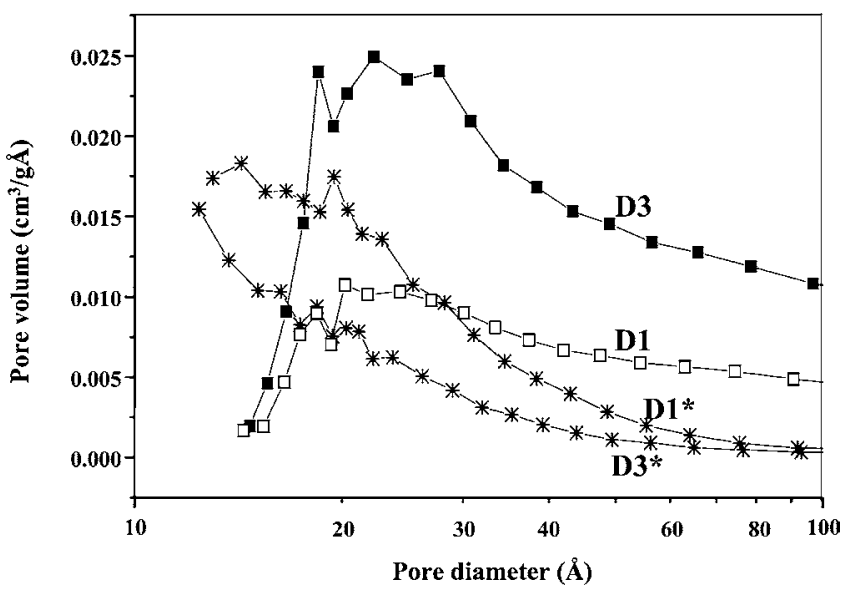

Figure 10. Pore size distributions for D1, D1*, D3, and D3* calculated using the $\mathrm{BJH}$ equation using the adsorption branch of the $\mathrm{N}_{2}$ adsorption isotherm at $80 \mathrm{~K}$.

be a correlation between the pore volume in the $<3 \mathrm{~nm}$ range and hydrogen storage.

The pore size distributions as calculated using the $\mathrm{BJH}$ equation are shown in Figure 10 for D1-D3 and D1*-D3*. In the less than $5 \mathrm{~nm}$ range, the distribution consists of three peaks at 2.0, 2.2, and $2.8 \mathrm{~nm}$. The pores at 2.2 and $2.8 \mathrm{~nm}$ are high in D3, which showed the highest ASH, and decrease drastically after purification for D3*, which showed the lowest ASH (Table 1). These pores could arise from nanostructured disordered carbon. However, note that D3 and D3* were also 
extremes in SSA (Table 1). The case of D1-D1* is somewhat different, since the ASH for D1 is higher than for D1*, despite D1 having both a lower SSA and pore volume $<3 \mathrm{~nm}$ (Table 1). The pore at $2.0 \mathrm{~nm}$ is increased after nitric acid treatment and could be related to adsorption inside the CNTs, perhaps reflecting some degree of CNTs opening.

The argon treatment does not change the pore distributions significantly (not shown in the figure) showing that the empty nanoshells do not contribute to the SSA and porosity of the samples.

\section{Conclusions}

The hydrogen storage at room temperatures and $10 \mathrm{MPa}$ pressure was studied in carbon nanotubes (mostly single- and double-walled) prepared by a catalytic chemical vapor deposition method. Under these conditions, the maximum hydrogen storage obtained is $0.5 \mathrm{wt} \%$. This value for hydrogen storage is much lower than that reported by Dillon et al. ${ }^{1}$ but is in good agreement with those reported in the review by Zuettel et al. ${ }^{8}$ Purification of the carbon nanotubes by oxidative acid treatments or by heating in inert gas decreases the hydrogen storage. Decreasing the residual catalyst content does not necessarily lead to an increase in ASH. Also, increasing the specific surface area does not necessarily increase the hydrogen storage capacity. There seems to be a correlation between the pore volume at low pore diameters $(<3 \mathrm{~nm})$ and hydrogen storage capacity. Contribution from nanoscale disordered carbon to the hydrogen storage cannot be ruled out. An in-depth characterization of carbon nanotubes samples, as-prepared and after purification, is essential in order to try and understand the complex phenomena involved in hydrogen storage.

Acknowledgment. The authors would like to thank Miss C. Maziarz and Miss M.-C. Barthélémy for their help in the preparation of carbon nanotubes and Mr. L. Datas for his assistance in the TEM observations, which have been performed at the Service Commun de Microscopie Electronique à Transmission, Université Paul-Sabatier.

\section{References and Notes}

(1) Dillon, A. C.; Jones, K. M.; Bekkedahl, T. A.; Kiang, C. H.; Bethune, D. S.; Heben, M. J. Nature (London) 1997, 386, 377.

(2) Maddox, M. W.; Gubbin, K. E. Langmuir 1995, 11, 2988.

(3) Darkrim, F. L.; Levesque, D. J. Phys. Chem. B 2000, 104, 6773.

(4) Rzepka, M.; Lamp, P.; de la Casa-Lillo, M. A. J. Phys. Chem. B 1998, 102, 10894.

(5) Ye, Y.; Ahn, C. C.; Witham, C.; Fultz, B.; Liu, J.; Rinzler, A. C.; Colbert, D.; Smith, K. A.; Smalley, R. E. Appl. Phys. Lett. 1999, 74, 2307.

(6) Shiraishi, M.; Takenobu, T.; Yamada, A.; Ata, M.; Kataura, H. Chem. Phys. Lett. 2002, 358, 213. 633.

(7) Shiraishi, M.; Takenobu, T.; Ata, M. Chem. Phys. Lett. 2003, 367,

(8) Züttel, A.; Nützenadel, Ch.; Sudan, P.; Mauron, Ph.; Emmenegger, Ch.; Rentsch, S.; Schlapbach, L.; Weidenkaff, A.; Kiyobayashi, T. J. Alloys Compd. 2002, 330-332, 676.

(9) Flahaut, E.; Peigney, A.; Laurent, Ch.; Rousset, A. J. Mater. Chem. 2000, 10, 249.

(10) Bacsa, R. R.; Laurent, Ch.; Peigney, A.; Bacsa, W.; Vaugien, T.; Rousset, A. Chem. Phys. Lett. 2000, 323, 526.

(11) Peigney, A.; Laurent, Ch.; Flahaut, E.; Bacsa, R. R.; Rousset, A. Carbon 2001, 39, 507.

(12) Flahaut, E.; Bacsa, R. R.; Peigney, A.; Laurent, Ch. Chem. Commun. 2003, 1442

(13) Bacsa, R. R.; Laurent, Ch.; Peigney, A.; Vaugien, T.; Flahaut, E.; Bacsa, W.; Rousset, A. J. Am. Ceram. Soc. 2002, 85, 2666.

(14) Flahaut, E.; Peigney, A.; Laurent, Ch.; J. Nanosci. Nanotech. 2003, 3,151 .

(15) Liu, J.; Rinzler, A. G.; Dai, H.; Hafner, J. H.; Bradley, R. K.; Boul, P. J.; Lu, A.; Iverson, T.; Shelimov, K.; Huffman, C. B.; Rodriguez-Macias, F.; Shon, Y.-K.; Lee, T. R.; Colbert, D. T.; Smalley, R. E. Science 1998, $280,1253$.

(16) Nagasawa, S.; Yudasaka, M.; Hirahara, K.; Ichihashi, T.; Iijima, S. Chem. Phys. Lett. 2000, 328, 374

(17) Chiang, I. W.; Brinson, B. E.; Huang, A. Y.; Willis, P. A.; Bronikowski, M. J.; Margrave, J. L.; Smalley, R. E.; Hauge, R. H. J. Phys. Chem. B 2001, 105, 8297.

(18) Hirscher, M.; Becher, M.; Haluske, M.; Quintel, A.; Skakalova, V.; Choi, Y.-M.; Dettlaff-Weglikowska, U.; Roth, S.; Stepanek, I.; Bernier, P.; Leonhardt, A.; Fink, J. J. Alloys Compd. 2002, 300-332, 654.

(19) Bacsa, R.; Peigney, A.; Laurent, Ch.; Puech, P.; Bacsa, W. Phys. Rev. B 2002, 65, 161404-1. 